\title{
Laparoscopic Sacrocolpopexy Plus Colporrhaphy With an Small Intestine Submucosa Graft Versus Total Pelvic Floor Reconstruction for Advanced Prolapse: A Retrospective Cohort Study
}

\author{
Junyan Wang ${ }^{1,2, *}$, Xiaojuan Wang ${ }^{1,2,}$, Keqin Hua ${ }^{1,2}$, Yisong Chen ${ }^{1,2}$ \\ ${ }^{1}$ Department of Gynecology, Obstetrics and Gynecology Hospital, Fudan University, Shanghai, China \\ ${ }^{2}$ Shanghai Key Laboratory of Female Reproductive Endocrine Related Diseases, Shanghai, China
}

Purpose: Transvaginal mesh (TVM) results in a greater anatomic cure but more complications. We aimed to compare laparoscopic sacrocolpopexy (LSC) plus colporrhaphy with the small intestine submucosa (SIS) graft versus TVM for advanced pelvic organ prolapse (POP).

Methods: Patients with advanced POP who underwent LSC plus colporrhaphy with the SIS graft or TVM at a center between September 2015 and November 2016 were studied. Anatomical outcomes were evaluated using POP quantification. Functional outcomes related to POP and sexual life were evaluated using the Pelvic Floor Distress Inventory (PFDI-20) and the Pelvic Organ Prolapse/Urinary Incontinence Sexual Function Questionnaire (PISQ-12). Data regarding surgical procedures and patient demographic variables were recorded. Chi-square and Student $\mathrm{t}$-tests were used for 2 independent samples.

Results: A total of 76 patients were enrolled in this study with 26 patients in the LSC plus colporrhaphy with the SIS graft group (group A) and 50 patients with TVM group (group B). All patients in both groups demonstrated significant improvement in anatomical outcomes $(\mathrm{P}<0.05)$ after surgery. PFDI-20 scores were significantly improved 12 months after operation in both groups $(\mathrm{P}<0.001)$. PISQ-12 scores were significantly improved in patients after surgery, especially patients in group A $(\mathrm{P}<0.001)$. Mesh exposure occurred in both groups as follows: 8 patients (30.7\%) in group A and 5 patients $(10 \%)$ in group B. Conclusions: Even though both surgeries showed excellent results for subjective and objective outcomes, the use of an SIS graft might increase the exposure of polypropylene mesh. We do not recommend LSC plus colporrhaphy with the SIS graft for advanced multiple-compartments prolapse.

Keywords: Pelvic organ prolapse; Small intestine submucosa graft; Sacrocolpopexy; Transvaginal mesh

- Grant/Fund Support: The study was supported by grants from the Science and Technology Commission of Shanghai Municipality (No.16411963700) and General Program from Shanghai Municipal Commission of Health and Family Planning (No. 201540155).

- Research Ethics: This study was approved by the Ethics Committee and the Institutional Review Board of Obstetrics and Gynecology Hospital,

Fudan University (No. 2016-11). Written or oral informed consent was obtained from all participants.

- Conflict of Interest: No potential conflict of interest relevant to this article was reported.

Corresponding author: Yisong Chen (iD https://orcid.org/0000-0002-2639-8753 Department of Gynecology, Obstetrics and Gynecology Hospital, Fudan University, 128 Shenyang Road, Shanghai 200090, China E-mail: cys373900207@qq.com / Tel: +86-13601913713 / Fax: +86-21-63455090 Co-corresponding author: Keqin Hua (D) https://orcid.org/0000-0001-5359-8841 Department of Gynecology, Obstetrics and Gynecology Hospital, Fudan University, 128 Shenyang Road, Shanghai 200090, China

E-mail: huakeqinjiaoshou@163.com / Tel: +86-21-33189900 / Fax: +86-21-63455090 *Junyan Wang and Xiaojuan Wang contributed equally to this study as co-first authors. Submitted: January 14, 2019 / Accepted after revision: February 27, 2019 (c) $\$$ BY $\$$ This is an Open Access article distributed under the terms of the Crecommons.org/licenses/by-nc/4.0/) which permits unrestricted non-commercial use, distribution, and reproduction in any medium, provided the original work is properly cited. 


\section{INTRODUCTION}

Pelvic organ prolapse (POP) is a major healthcare problem for elderly women worldwide and has a serious impact on the quality of life. The prevalence rates of POP varied from $41 \%$ to $75 \%$ [1-3]. Surgery is the main treatment for advanced POP [4]. Since the introduction of polypropylene mesh for POP in the late 1990s, evidence from randomized trials has shown that transvaginal mesh (TVM) resulted in greater treatment rates than native tissue surgery [5]. Over the years, TVM has ever become a global treatment for POP and has been entered in main surgery in majority pelvic floor surgery centers worldwide [6].

However, the high complications, such as mesh exposure, pelvic pain, and dyspareunia, related to synthetic mesh resulted in warnings from the U.S. Food and Drug Administration in 2008 and 2011 [7]. To decrease mesh-associated complications and improve anatomical outcomes, biological grafts were used as alternatives to synthetic mesh, and grafts derived from cadavers and animal-derived collagen matrices were developed [8]. Culligan et al. [9] compared the surgical outcomes 12 months after laparoscopic sacrocolpopexy (LSC) with porcine dermis and that with polypropylene mesh and found that both had similar outcomes in subjective or objective results. Feldner et al. [8] compared the small intestine submucosa (SIS) graft with traditional colporrhaphy for surgical treatment of anterior vaginal prolapse and found that SIS repair improved point $\mathrm{Ba}$ significantly. Liang et al. [10] used complete and nonsplice SIS patches for total pelvic anatomical repair of organ prolapse in 17 patients and found that one patient experienced stage II anterior vaginal wall prolapse after surgery and no organ damage, infection, erosion, or rejection was observed.

Additionally, sacrocolpopexy is the gold standard for the treatment of advanced apical prolapse [11], which is associated with fewer complications. There are few publications about LSC plus colporrhaphy with an SIS graft for advanced POP. Here, we aimed to compare anatomic and functional outcomes after the treatment of advanced POP by LSC plus colporrhaphy with an SIS graft versus TVM.

\section{MATERIALS AND METHODS}

This study was approved by the Ethics Committee and the Institutional Review Board of Obstetrics and Gynecology Hospital. For this retrospective study, data were analyzed from pa- tients who underwent LSC plus colporrhaphy with SIS graft (group A) or TVM (group B) at a tertiary university-affiliated hospital between September 1, 2015 and November 30, 2016. All patients who underwent the above surgical procedures were diagnosed with stage III genital prolapse in at least 2 parts according to the Pelvic Organ Prolapse Quantification (POP-Q) system [11]. Patients with incomplete data, mental disorders, or death during follow-ups were excluded. This study has been reported in accordance with the STROCSS (Strengthening the Reporting of Cohort Studies in Surgery) criteria [12].

The demographic information included age, body mass index, parity, degree of prolapse upon examination, history of either prolapse surgery or hysterectomy and were recorded. Anatomical outcomes were based on POP-Q measurements by 2 experienced surgeons. Functional outcomes were assessed preoperatively and postoperatively by the validated Chinese version of the Pelvic Floor Distress Inventory questionnaire (PFDI20 ; range $0-80$, with higher scores indicating worse function), including the Pelvic Organ Prolapse Distress Inventory 6 (POPDI-6), the Colorectal-Anal Distress Inventory 8 (CRADI-8), the Urinary Distress Inventory 6 (UDI-6), and the Pelvic Organ Prolapse/Urinary Incontinence Sexual Function Questionnaire (PISQ-12; range $0-80$, with higher scores indicating better function) $[13,14]$.

\section{Surgery Procedure}

LSC was performed using polypropylene mesh $(4 \mathrm{~cm} \times 10 \mathrm{~cm}$; Dynamesh, FEG Textiltechnik, Aachen, Germany), and all surgical procedures were performed as previously described [15]. A midline incision was made along the length of the anterior vaginal wall from the bladder neck to the vaginal apex, and the bladder was dissected from the vaginal mucosa by blunt or sharp dissection until the arcus tendineus bilaterally. The SIS graft was presoaked in saline solution and then cut into a trapezoidal shape based on the vaginal length. Then, the SIS graft was extended from the bladder neck to the vaginal apex and from one vaginal sulcus to the other without tension. Then, 0 -prolene was used to fix the graft by suturing the fascia of the arcus tendineus bilaterally. Similarly, posterior repair with the SIS graft was performed. The distal graft was fixed on the margin of the hymen, and the proximal graft was fixed on the vaginal apex. Depending on the site of prolapse, the SIS graft repair could be anterior, posterior, or both. TVM was performed using a synthetic monofilament polypropylene mesh (Gynecare Gynemesh, Ethicon Women's Health and Urology, Somerville, 
NJ, USA). The surgery was performed as previously described [16]. All surgical procedures were performed by 2 experienced urogynecologists. All patients underwent concurrent hysterectomies. Concurrent midurethral sling procedures were performed based on the outcomes of the urodynamic test and the symptoms of the patients. All procedures were performed under antibiotic coverage.

Surgical outcomes included duration of operation, estimated blood loss, injuries, postoperative hospitalization, fever (temperature $>38^{\circ} \mathrm{C}$ on 2 occasions), and complications (including mesh exposure, wound infection, and vaginal bleeding). Pelvic examination, including the POP-Q system, was performed at baseline, 6 months after surgery, and annually after surgery. Anatomic success was marked as the achievement of POP stage $<2$. Recurrence was defined as the presence of POP stage $\geq 2$ at the same site at 12 months after operation. Subjective improvements (including POP symptoms and sexual life) in PFDI-20 and PISQ-12 were assessed in follow-ups.

\section{Statistical Analysis}

Means and standard deviations were calculated for continuous variables, and frequencies (proportions) were calculated for categorical variables. Chi-square and Student $\mathrm{t}$-tests were used to calculate $\mathrm{P}$-values where appropriate for changes from preoperation to postoperation. A value of $\mathrm{P}<0.05$ was considered statistically significant. Statistical analysis was performed using SPSS ver. 16.0 (SPSS Inc., Chicago, IL, USA).

\section{RESULTS}

During the study period, 76 patients were enrolled for analysis. In total, 26 patients experienced LSC plus colporrhaphy with the SIS graft, 2 of them were performed concurrent midurethral sling (MUS); 50 patients underwent TVM, 5 of them were given MUS. There were no significant differences in age, body mass index, frequency of stress urinary incontinence, or other characteristics between the 2 groups (Table 1). The estimated blood loss during the operation was similar in both groups. However, the length of operation was significantly longer in LSC plus colporrhaphy with the SIS graft than in TVM $(\mathrm{P}<0.001)$. There were no blood transfusions in either group. One patient who underwent TVM experienced bladder injury and was given suturing during the operation and then recovered completely. Nine patients (34.6\%) underwent LSC plus colporrhaphy with the SIS graft experienced vaginal infection, which was significantly more than those who underwent TVM $(\mathrm{n}=7 ; 14 \%)(\mathrm{P}=0.038)$. Vaginal infection usually occurred 5 days postoperation and was proven to be infected with Escherichia coli or Enterococcus faecalis by culturing the vaginal discharge. Moreover, the postoperative hospital stay of group A was significantly longer than that of group $\mathrm{B}(\mathrm{P}<0.0001)$. Mesh exposure occurred in both groups, with 8 patients (30.7\%) in group A and 5 patients (10\%) in group $\mathrm{B}$, which was significantly different $(\mathrm{P}=0.027)$. These patients were successfully given mesh excision in outpatients. Patients with mesh exposure in group A were nearly the same as those

Table 1. Characteristics of the patients enrolled

\begin{tabular}{lccc}
\hline Characteristic & Group A $(\mathrm{n}=26)$ & Group B $(\mathrm{n}=50)$ & P-value \\
\hline Age $(\mathrm{yr})$ & $58 \pm 1.6256(42-70)$ & $59 \pm 0.9160(47-73)$ & 0.480 \\
Body mass index $\left(\mathrm{kg} / \mathrm{m}^{2}\right)$ & $23.7 \pm 2.4$ & $23.9 \pm 2.9$ & 0.220 \\
Age of menopause $(\mathrm{yr})$ & $52.63 \pm 1.06$ & $51.2 \pm 0.64$ & 0.240 \\
No. of children & $2(1-5)$ & $2(1-6)$ & 0.453 \\
Stress urinary incontinence & $9(34.6)$ & $18(36.7)$ & 0.870 \\
Menopause & $20(76.9)$ & $39(78.0)$ & 0.545 \\
Preoperative POP-Q scores & & & \\
Aa & $2.31 \pm 1.01$ & $2.38 \pm 0.95$ & 0.758 \\
Ba & $2.65 \pm 1.26$ & $2.88 \pm 1.15$ & 0.435 \\
C & $2.31 \pm 2.36$ & $2.02 \pm 2.68$ & 0.645 \\
Ap & $-0.23 \pm 2.10$ & $-0.24 \pm 2.13$ & 0.713 \\
Bp & $0.77 \pm 2.52$ & $0.78 \pm 2.71$ & 0.987 \\
TVL & $7.27 \pm 0.60$ & $7.26 \pm 0.69$ & 0.954 \\
\hline
\end{tabular}

Values are presented as mean \pm standard deviation (range), median (range), or number (\%).

Group A, laparoscopic sacrocolpopexy plus colporrhaphy with small intestine submucosa graft; group B, transvaginal mesh; POP-Q, pelvic organ prolapse quantification. 
Table 2. Perioperative outcomes by surgical groups

\begin{tabular}{lccc}
\hline Outcome & Group A $(\mathrm{n}=26)$ & Group B $(\mathrm{n}=50)$ & P-value \\
\hline Operative time (min) & $148.8 \pm 6.7$ & $94.22 \pm 3.46$ & $<0.0001$ \\
Blood loss (mL) & $121.2 \pm 9.68$ & $102.4 \pm 9.47$ & 0.212 \\
Blood transfusion & 0 & 0 & - \\
Injury & 0 & 1 & 0.238 \\
Postoperative fever & 10 & 25 & 0.038 \\
Vaginal apical infection & 9 & 7 & 0.027 \\
Mesh exposure & 8 & 5 & 0.54 \\
Pain & 4 & 11 & 0.237 \\
Postoperative urinary tract infection & 9 & 12 & $<0.0001$ \\
Postoperative hospital stays & $10.67 \pm 0.73$ & $6.9 \pm 0.35$ & \\
\hline
\end{tabular}

Values are presented as mean \pm standard deviation or number.

Group A, laparoscopic sacrocolpopexy plus colporrhaphy with small intestine submucosa graft; group B, transvaginal mesh.

Table 3. Anatomic outcomes measured by POP-Q at 2 timepoints after surgery

\begin{tabular}{|c|c|c|c|}
\hline Anatomical outcome & Group A $(n=26)$ & Group B $(n=50)$ & P-value \\
\hline \multicolumn{4}{|l|}{ 6-Month follow-up } \\
\hline $\mathrm{Aa}$ & $-2.77 \pm 0.430$ & $-2.78 \pm 0.431$ & 0.192 \\
\hline $\mathrm{Ba}$ & $-2.62 \pm 0.496$ & $-2.68 \pm 0.469$ & 0.423 \\
\hline $\mathrm{C}$ & $-6.54 \pm 0.650$ & $-6.48 \pm 0.614$ & 0.700 \\
\hline Ap & $-2.96 \pm 0.196$ & $-2.98 \pm 0.141$ & 0.639 \\
\hline $\mathrm{Bp}$ & $-2.92 \pm 0.271$ & $-2.94 \pm 0.239$ & 0.781 \\
\hline TVL & $7.23 \pm 0.429$ & $7.12 \pm 0.520$ & 0.355 \\
\hline \multicolumn{4}{|l|}{ 12-Month follow-up } \\
\hline Aa & $-2.69 \pm 0.471$ & $-2.76 \pm 0.431$ & 0.914 \\
\hline $\mathrm{Ba}$ & $-2.54 \pm 0.508$ & $-2.68 \pm 0.471$ & 0.050 \\
\hline $\mathrm{C}$ & $-6.50 \pm 0.648$ & $-6.44 \pm 0.611$ & 0.692 \\
\hline Ap & $-2.92 \pm 0.272$ & $-2.94 \pm 0.239$ & 0.781 \\
\hline $\mathrm{Bp}$ & $-2.88 \pm 0.326$ & $-2.92 \pm 0.274$ & 0.618 \\
\hline TVL & $7.23 \pm 0.429$ & $7.11 \pm 0.558$ & 0.380 \\
\hline
\end{tabular}

Values are presented as mean \pm standard deviation.

Group A, laparoscopic sacrocolpopexy plus colporrhaphy with small intestine submucosa graft; group B, transvaginal mesh; POP-Q, pelvic organ prolapse quantification.

with vaginal infection. Four women (15.4\%) who underwent LSC plus colporrhaphy with the SIS graft complained of pain in the pelvic area, which was relieved gradually after 3 months. The mentioned above patients with complications often had at least 2 complications. Eleven patients with TVM complained of blunt pelvic pain, which gradually diminished after 4 months. The above results are shown in Table 2.

Anatomic success (POP stage $\leq$ I) in the LSC plus colporrhaphy with the SIS graft group at 12 months was $92.3 \%$ (95\% confidence interval [CI], 81.3\%) and 96\% (95\% CI, 90.4\%-101.6\%) in the TVM group. Anatomic outcomes based on POP-Q scores were greatly improved in both groups (Table 3 ). The average
POP-Q Aa score was shorter in the TVM group than in the LSC plus colporrhaphy with the SIS graft group at the 12-month follow-up $(\mathrm{P}=0.05)$. No differences in $\mathrm{Ba}, \mathrm{Ap}$, Bp, or $\mathrm{C}$ scores were observed in either group at the follow-ups.

PFDI-20 scores were significantly improved 12 months after operation in both groups $(\mathrm{P}<0.001)$ (Table 4). Subjective improvement was reported at the 12-month follow-up by 24 of 26 women (92.3\%) in the LSC plus colporrhaphy with the SIS graft group and 46 of 50 women (92\%) in the TVM group $(\mathrm{P}=0.667)$. When inventories were analyzed separately, POPDI- 6 scores and UDI-6 scores were significantly improved in both groups at the 12-month follow-up $(\mathrm{P} \leq 0.001)$. Regarding the CRADI-8 
Table 4. Functional outcomes at two timepoints after surgery

\begin{tabular}{|c|c|c|c|}
\hline Functional outcomes & Group A $(n=26)$ & Group B $(\mathrm{n}=50)$ & P-value \\
\hline $\begin{array}{l}\text { PFDI-20 score } \\
\text { Preoperative } \\
\text { 12-Month follow-up } \\
\text { P-value }\end{array}$ & $\begin{array}{l}48.88 \pm 14.89 \\
17.63 \pm 7.10 \\
<0.001\end{array}$ & $\begin{array}{l}55.19 \pm 17.02 \\
17.94 \pm 7.80\end{array}$ & $\begin{array}{l}0.114 \\
0.866\end{array}$ \\
\hline $\begin{array}{l}\text { POPDI-6 score } \\
\text { Preoperative } \\
\text { 12-Month follow-up } \\
\text { P-value }\end{array}$ & $\begin{array}{c}23.39 \pm 10.20 \\
7.21 \pm 6.19 \\
<0.001\end{array}$ & $\begin{array}{c}26.08 \pm 11.10 \\
7.92 \pm 6.69 \\
<0.001\end{array}$ & $\begin{array}{l}0.308 \\
0.656\end{array}$ \\
\hline $\begin{array}{l}\text { UDI-6 score } \\
\text { Preoperative } \\
\text { 12-Month follow-up } \\
\text { P-value }\end{array}$ & $\begin{array}{c}18.75 \pm 6.99 \\
6.57 \pm 2.68 \\
<0.001\end{array}$ & $\begin{array}{c}21.41 \pm 8.74 \\
6.08 \pm 2.82 \\
<0.001\end{array}$ & $\begin{array}{l}0.183 \\
0.470\end{array}$ \\
\hline $\begin{array}{l}\text { CRADI-8 score } \\
\text { Preoperative } \\
\text { 12-Month follow-up } \\
\text { P-value }\end{array}$ & $\begin{array}{c}6.73 \pm 4.20 \\
3.85 \pm 2.04 \\
0.003\end{array}$ & $\begin{array}{c}7.68 \pm 4.69 \\
3.93 \pm 2.17 \\
<0.001\end{array}$ & $\begin{array}{l}0.386 \\
0.859\end{array}$ \\
\hline $\begin{array}{l}\text { PISQ-12 score } \\
\text { Preoperative } \\
\text { 12-Month follow-up } \\
\text { P-value }\end{array}$ & $\begin{array}{c}10.54 \pm 3.23 \\
16.23 \pm 3.79 \\
<0.001\end{array}$ & $\begin{array}{c}11.02 \pm 3.67 \\
14.14 \pm 3.85 \\
0.001\end{array}$ & $\begin{array}{l}0.574 \\
0.027\end{array}$ \\
\hline
\end{tabular}

Values are presented as mean \pm standard deviation.

Group A, laparoscopic sacrocolpopexy plus colporrhaphy with an small intestine submucosa graft; group B, transvaginal mesh; PDFI-20, Pelvic Floor Distress Inventory-20; POPDI, Pelvic Organ Prolapse Distress Inventory; UDI, Urinary Distress Inventory; CARDI, Colorectal-Anal Distress Inventory; PISQ, Pelvic Organ Prolapse/Urinary Incontinence Sexual Function Questionnaire.

scores, colorectal symptoms were also improved in both groups. In terms of sexual function, 65 patients from both groups were sexually active preoperation, and all of them completed a PISQ12 questionnaire. There was a statistically significant improvement in these patients after surgery, especially those who underwent LSC combined with colporrhaphy with the SIS graft $(\mathrm{P}<$ 0.001) (Table 4).

\section{DISCUSSION}

It is well known that mesh sacrocolpopexy is the preferred surgical option for apical prolapse [17] and is associated with fewer complications. This present study revealed that LSC plus colporrhaphy with the SIS graft had the same outcomes as TVM in improved anatomic and functional outcomes in patients with advanced POP. The objective outcomes were $95 \%$ in patients who underwent LSC plus colporrhaphy with absorbable mesh and 92\% in patients who underwent TVM, which were similar to previous studies [18]. The subjective outcomes based on validated questionnaires were $92.3 \%$ in the LSC plus colporrhaphy with absorbable mesh group and $92 \%$ in the TVM group, demonstrating similar improvements in the quality of life reported in previous studies $[19,20]$.

At more than 1-year follow-up in this study, although the overall success rate was similar, the improvement of sexual function in the LSC plus colporrhaphy with an SIS graft group seemed better than that in the TVM group. Due to cultural reasons, many women in China are reluctant to discuss their sexual experience, which is why our PISQ scores were apparently lower before surgery compared to other studies [21]. In addition, women in the LSC plus colporrhaphy with the SIS graft group achieved better sexual function than that in the TVM group, and this result may be due to longer TVL, absorbable grafts, or both.

The laparoscopic approach should facilitate a more precise anatomic repair and faster recovery. However, the incidence of vaginal infection in the LSC plus colporrhaphy with the SIS graft group was significantly higher than that in the TVM group, and hospital stays were also longer. Vaginal infection usually occurred 5-day postoperation and was proven to be caused by E. coli or E. faecalis by culturing the vaginal discharge; vaginal infection may result in vaginal apical mesh exposure 
later. The reasons for this result might be due to the greater degree of skill, extensive specialized training required, longer operative duration, and graft itself [20]. Due to higher complications, we terminated this LSC plus colporrhaphy with the SIS graft for advanced POP; thus, there were only 26 patients enrolled in our study. However, with good anatomical outcomes and substantial improvement of sexual function, LSC plus colporrhaphy with the SIS graft could be considered as an option for treating advanced POP but with extra precaution against vaginal infection, which may increase mesh exposure [22].

The strength of our study included that validated questionnaires were used to preoperatively and postoperatively evaluate every participant. In addition, every woman in our study had follow-ups for at least 1.5 years after surgery, which was longer than most publications. However, there were several limitations to our study. First, this study has the inherent weakness of being a retrospective study. Second, the sample size could be inadequate to detect small differences in the groups, and the power calculation was suboptimal. Further studies with larger samples and longer follow-ups are required to validate the above outcomes.

In conclusion, both surgeries showed excellent results for anatomical outcomes and quality of life after surgeries. The sexual functional improvement in LSC plus colporrhaphy with the SIS graft group was better than that in TVM group. However, the use of SIS graft might increase the exposure of polypropylene mesh exposure. Therefore, we do not recommend LSC plus colporrhaphy with the SIS graft for advanced multiple-compartments prolapse.

\section{AUTHOR CONTRIBUTION STATEMENT}

- Full access to all the data in the study and takes responsibility for the integrity of the data and the accuracy of the data analysis: $Y C, K H$

- Study concept and design: $Y C$

- Acquisition of data: XW

- Analysis and interpretation of data: $X W$

- Drafting of the manuscript: JW

- Critical revision of the manuscript for important intellectual content: $K H$

- Statistical analysis: $J W$

- Obtained funding: $Y C$

- Administrative, technical, or material support: $K H$

- Study supervision: $K H$

\section{REFERENCES}

1. Barber MD, Maher C. Epidemiology and outcome assessment of pelvic organ prolapse. Int Urogynecol J 2013;24:1783-90.

2. Swift S, Woodman P, O'Boyle A, Kahn M, Valley M, Bland D, et al. Pelvic Organ Support Study (POSST): the distribution, clinical definition, and epidemiologic condition of pelvic organ support defects. Am J Obstet Gynecol 2005;192:795-806.

3. Wilkins MF, Wu JM. Epidemiology of pelvic organ prolapse. Curr Obstet Gynecol Rep 2016;5:119-23.

4. Elterman DS, Chughtai BI, Vertosick E, Maschino A, Eastham JA, Sandhu JS. Changes in pelvic organ prolapse surgery in the last decade among United States urologists. J Urol 2014;191:1022-7.

5. Altman D, Väyrynen T, Engh ME, Axelsen S, Falconer C; Nordic Transvaginal Mesh Group. Anterior colporrhaphy versus transvaginal mesh for pelvic-organ prolapse. N Engl J Med 2011;364:182636.

6. Kasyan G, Abramyan K, Popov AA, Gvozdev M, Pushkar D. Meshrelated and intraoperative complications of pelvic organ prolapse repair. Cent European J Urol 2014;67:296-301.

7. Murphy M, Holzberg A, van Raalte H, Kohli N, Goldman HB, Lucente $\mathrm{V}$, et al. Time to rethink: an evidence-based response from pelvic surgeons to the FDA Safety Communication: "UPDATE on Serious Complications Associated with Transvaginal Placement of Surgical Mesh for Pelvic Organ Prolapse”. Int Urogynecol J 2012; 23:5-9.

8. Feldner PC Jr, Castro RA, Cipolotti LA, Delroy CA, Sartori MG, Girão MJ. Anterior vaginal wall prolapse: a randomized controlled trial of SIS graft versus traditional colporrhaphy. Int Urogynecol J 2010;21:1057-63.

9. Culligan PJ, Salamon C, Priestley JL, Shariati A. Porcine dermis compared with polypropylene mesh for laparoscopic sacrocolpopexy: a randomized controlled trial. Obstet Gynecol 2013;121:14351.

10. Liang X, Zhang L, Lv Y. Treatment of total pelvic organ prolapse using a whole biological patch: A pilot study of 17 patients. J Obstet Gynaecol Res 2017;43:164-72.

11. Haylen BT, Freeman RM, Lee J, Swift SE, Cosson M, Deprest J, et al. International Urogynecological Association (IUGA)/International Continence Society (ICS) joint terminology and classification of the complications related to native tissue female pelvic floor surgery. Neurourol Urodyn 2012;31:406-14.

12. Agha RA, Borrelli MR, Vella-Baldacchino M, Thavayogan R, Orgill DP; STROCSS Group. The STROCSS statement: Strengthening the Reporting of Cohort Studies in Surgery. Int J Surg 2017;46:198-202. 
13. Zhu L, Yu S, Xu T, Yang X, Lu Y, Lang J. Validation of the Chinese version of the Pelvic Organ Prolapse/Urinary Incontinence Sexual Questionnaire short form (PISQ-12). Int J Gynaecol Obstet 2012; 116:117-9.

14. Barber MD, Walters MD, Bump RC. Short forms of two conditionspecific quality-of-life questionnaires for women with pelvic floor disorders (PFDI-20 and PFIQ-7). Am J Obstet Gynecol 2005;193: 103-13.

15. Chen Y, Hua K. Medium-term outcomes of laparoscopic sacrocolpopexy or sacrohysteropexy versus vaginal sacrospinous ligament fixation for middle compartment prolapse. Int J Gynaecol Obstet 2017;137:164-9.

16. Zhu L, Lang J, Sun Z, Ren C, Liu X, Li B. Pelvic reconstruction with mesh for advanced pelvic organ prolapse: a new economic surgical method. Menopause 2011;18:328-32.

17. Siddiqui NY, Grimes CL, Casiano ER, Abed HT, Jeppson PC, Olivera CK, et al. Mesh sacrocolpopexy compared with native tissue vaginal repair: a systematic review and meta-analysis. Obstet Gynecol 2015;125:44-55.
18. Schimpf MO, Abed H, Sanses T, White AB, Lowenstein L, Ward $\mathrm{RM}$, et al. Graft and mesh use in transvaginal prolapse repair: a systematic review. Obstet Gynecol 2016;128:81-91.

19. Balzarro M, Rubilotta E, Porcaro AB, Trabacchin N, Sarti A, Cerruto MA, et al. Long-term follow-up of anterior vaginal repair: a comparison among colporrhaphy, colporrhaphy with reinforcement by xenograft, and mesh. Neurourol Urodyn 2018;37:278-83.

20. Lo TS, Tan YL, Cortes EF, Pue LB, Wu PY, Al-Kharabsheh A. Anterior-apical single-incision mesh surgery (SIMS): surgical and functional outcomes at 1 year. J Minim Invasive Gynecol 2015;22: 50-6.

21. Schiavi MC, Perniola G, Di Donato V, Visentin VS, Vena F, Di Pinto $A$, et al. Severe pelvic organ prolapse treated by vaginal native tissue repair: long-term analysis of outcomes in 146 patients. Arch Gynecol Obstet 2017;295:917-22.

22. Cheng YW, Su TH, Wang H, Huang WC, Lau HH. Risk factors and management of vaginal mesh erosion after pelvic organ prolapse surgery. Taiwan J Obstet Gynecol 2017;56:184-7. 